\title{
Emotional Intelligence among Business Consultants: A Comparative Study
}

\author{
Fonthip Sarinnapakorn ${ }^{1} \&$ Usaporn Sucaromana ${ }^{2}$ \\ ${ }^{1}$ Business English for International Communication, Srinakharinwirot University, Bangkok, Thailand \\ ${ }^{2}$ Department of Western Languages, Faculty of Humanities, Srinakharinwirot University, Bangkok, Thailand \\ Correspondence: Usaporn Sucaromana, Faculty of Humanities, Srinakharinwirot University, Sukhumvit 23 Rd., \\ Bangkok 10110, Thailand. Tel: 66-2-649-5545. E-mail: usaporn@swu.ac.th
}

\author{
Received: December 21, 2012 Accepted: January 17, 2013 Online Published: February 4, 2013 \\ doi:10.5539/ass.v9n3p1 \\ URL: http://dx.doi.org/10.5539/ass.v9n3p1
}

\begin{abstract}
This study aimed to investigate the levels of emotional intelligence (EI) of business consultants who work for a consulting firm in Bangkok, Thailand, and to compare the EI levels of these consultants based on gender and years in the industry. A questionnaire adapted from the theoretical framework of Goleman (1995) was completed by 80 business consultants. This instrument comprised of 45 items that can be grouped into fives EI competencies referred to as: (a) self-awareness, (b) self-regulation, (c) motivation, (d) empathy, and (e) social skills. The results were calculated in terms of percentages, mean scores, and standard deviations. T-test was also employed to determine the differences between levels of EI and the independent variables which are gender and years in the industry. The results revealed that the EI level of the business consultants was at a high level. However, there was no significant difference between levels of EI based on gender and years in the industry.
\end{abstract}

Keywords: emotional intelligence, business consultants, consulting, emotional quotient, competencies

\section{Introduction}

The term Emotional Intelligence or EI is a well-researched topic since Goleman (1995) argued in his book that EI was the most important factor in personal adjustment, success in relationships, and in job performance. Several researchers indicated that EI competency had positive effects on an organization. For example, Cherniss (2001) pointed out that EI was an essential part of most organizations as it was used as a tool in the recruitment process, as well as in practical training for individuals and groups. Similarly, according to the study of Zeidner, Matthews, and Roberts (2004), EI skills might be a vital component of any organization's management. Goleman (1998) stated that people who had high EI levels were more able to connect with people in a way that gained the person's interest. This meant they had a greater chance of successfully achieving their goals. Mayer and Salovey (1997), and Sjoberg (2001) explained that EI helped with the social skills that were needed to perform alongside others in a team environment. Managers with high EI levels were also thought to be able to manage their workforce more effectively while achieving more employee loyalty resulting in more commitment to the firm from their subordinates (Cherniss, 2001).

Zeidner, Matthews, and Roberts (2004) also stated that EI affected a wide array of work behaviors, including employee commitment, teamwork, innovation, quality of service, and customer loyalty. Cooper (1997, cited in Mulder, 2009) asserted that people with high levels of EI experienced more career success, built stronger personal relationships, lead more effectively, and enjoyed better health than those with low EI levels. Likewise, Cherniss (2001) stated that EI is linked to the ability to manage emotion in oneself and others that were predictive of good performance in work roles. It can therefore be concluded that EI plays an important roles in contemporary workplaces, since it has positive effects on organizations, such as cultivating better work performance, employee commitment, and effective management among leaders.

Most organizations especially those in the service industry; for example, consulting business services use EI tests in the recruitment process (Hudak, 2000). Macalam (2009) states that business consultant's role is to help form solutions for businesses and to solve organizational problems by working closely with clients. The steps that have to be gone through include identifying what the company wants by collecting data, then analyzing where the problems may lie and formulating a plan proposal to rectify these issues. This proposal should be 
accompanied by an outline of tasks, the personnel needed to carry out the tasks, a time frame for the results to be gained, and the necessary budget. Both the plan and the outline will then be tailor made to client requests through a process of seeing what the best parts of the solutions are for them and taking on board any feedback they give during a presentation. The main responsibility of a business consultant is to successfully advise clients how they can achieve business growth. Many organizations therefore feel compelled to reconsider their business strategies due to the high level of competition in some sectors.

Due to the responsibilities of business consulting services, most consulting firms prefer to hire highly qualified business consultants who have good educational background and qualifications, specialist knowledge in the field, as well as years of experience to ensure that they will be able to serve client needs. Oginska-Bulik (2005) stated that to be successful in the human services industry, a person requires certain skill-sets and competencies. They need to possess sufficient knowledge and skills to complete a task, be able to motivate employees, improve working conditions, and be able to identify customer behavior and expectations. These skills are similar to EI competencies, since EI is deemed to be a major contributor to overall work performance (Mishra \& Mohapatra, 2010). In other words, it has been claimed that people with high EI level experience more career success, build stronger personal relationships, supervise their subordinates more effectively, and have more healthy working conditions than people with low EI (Cooper, 1997). With the skills listed above, it is useful to measure EI levels among business consultants by using the EI framework. Therefore, this study aimed to investigate the levels of emotional intelligence (EI) of business consultants who work for a consulting firm in Bangkok, and to compare the EI levels of these consultants based on gender and years in the industry. In response to the objectives of the study, two research questions are proposed:

1) What are the levels of EI among business consultants who work for a consulting firm in Bangkok?

2) Are there any significant differences in the EI of these business consultants based on gender and years of in the industry?

\section{Literature Review}

Numerous influential researchers have defined the term Emotional Intelligence. Goleman (1998) defined EI as "the capacity for recognizing our own feelings and those of others, for motivating ourselves and for managing emotions well in ourselves and in our relationships" (p. 317). Besides, Cooper and Sawaf (1997) stated that if people are able to identify emotions of their own and those of other people, then they are socially intelligent. EI allows people to separate these emotions and target them with whatever is needed to satisfy that emotion. According to Mayer and Salovey (1990), the definition of EI includes "the ability to monitor's one own and others' feelings and emotions, to discriminate among them and to use this information to guide one's thinking and actions" (p. 189). This is similar to the definition by Schutte, Malouff, Hall, Haggerty, Cooper, Golden, and Dornhein (1998), who stated that people who have EI are able to identify feelings, show feelings, manage feelings, and use them in a productive way.

Goleman (1995) developed the EI framework based on the belief that an individual could reach their highest potential by developing skills in five competencies including (a) self-awareness, (b) self-regulation, (c) motivation, (d) empathy, and (e) social skills. Self-awareness is considered an important element of EI since it refers to the ability of a person to be able to identify and control his or her own feelings, thoughts and needs. In terms of work or business, self-awareness may also be significant because most employees may need to work with others, or have the desire to do so. They are often required to work as a member of a team, and may need to interact directly with clients. Therefore, this ability is necessary as it allows an individual to act, or behave appropriately with others.

Another important EI model of Goleman's framework is self-regulation. This is the ability to control personal emotions and impulses. A person with high levels of EI is able to control their emotions. In situations in which an individual has different ideas or opinions to their clients, negative feelings might arise. However, with the ability to self-regulate, they are able to respond appropriately, regardless of their personal feelings. Assanova and McGuire (2009) identified self-regulation as being able to adapt to change with ease, dealing with things with integrity, thoughtfulness and the ability to say 'no' when needed. Motivation is another main element of the EI framework. A person with motivational elements is the kind of individual who always sets high goals, and then sets out to achieve them. A person with a high level of EI always initiates new ideas, and tries to find better ways of achieving outcomes in their work. Motivation is beneficial in a person's life as it makes a person feel that their life is meaningful. In turn, they will try their best to achieve their personal goals. Empathy is the ability of a person to understand the feelings of others. Sometimes, a person is not always able to put their needs and wants first. Often, it is necessary to consider the feelings and needs of others. This is especially true in the workplace 
where a person with high EI levels should be able to recognize the feeling of others and identify problems. For example, a person who is not recognized or appreciates other people's efforts in the workplace is a result of a lack of empathy (Johnson \& Erb, 2003). The last element of Goleman's theory is social skills. A person who has these skills is expected to have reasonably good communication skills. In a working environment, effective communication between superiors and their subordinates is vital. Without communication, they are unable to work together to reach their goals.

Numerous researchers have studied EI and the significance it has played in academic and work achievement in a person's life. Goleman (1995) stated that since EI is not what people are born with, several researchers attempted to discover if the competencies of EI could be developed. Goleman explained that EI can be learned and developed through training and guidance, while IQ is relatively fixed. This statement is relevant to the study of Serrat (2009) who stated that people can learn EI through self-motivation, practicing what they have already learned, getting feedback, and reinforcing new skills. Serrat also pointed out that if a person can enhance their EI, they can become more productive and successful. Similarly, previous research from Feldman and Mulle (2007) showed that EI competencies may result from behaviours that are scaled in development. They stated that EI competencies can be developed through training and practice so that a person with EI would become more competent. This is similar to Bar-On (2000), who found that a person can develop their EI levels through life experience.

Several Thai researchers have also been interested in research on this topic. Most of them studied the concept of EI in terms of academic achievement among students and the career accomplishments of individuals, teams, and organizations in the workplace. According to the results of research conducted by Intarakamhaeng and Sucaromana (2005) in Synthesis of Research Studies in Thailand related to Emotional Intelligence, only a limited number of research studies have concentrated on EI related to work environments. The samples of the studies were students, ranging from pre-school to university undergraduate level, and working people, ranging from government officers, general public employees, and service employees in the private sector.

There are several published research studies that investigate the levels of EI among working people in Bangkok, even though EI has been mainly studied in the area of job performance. However, there are no specific studies that investigate EI levels among business consultants. Therefore, the specific problem addressed in this study is to examine the levels of EI among business consultants who work for a consulting firm in Bangkok. In addition, there are also only limited studies that identified if gender and years in the industry have any significant difference to EI levels among business consultants.

\section{Methodology}

\subsection{Participants}

The participants of this study consisted of 80 business consultants who currently work for a consulting firm in Bangkok. The researcher chose the target group in this firm because of its well - known reputation, and this firm were ranked in one of the big four consulting firm of the world. Of the total participants, $39(48.75 \%)$ were males, while $41(51.25 \%)$ were females. Approximately, $65 \%$ of the participants had worked in the industry for three years and more, while $35 \%$ of the participants had worked in the industry less than three years.

\subsection{Research Instrument}

To investigate the level of EI among the business consultants, this study used a questionnaire that was developed in accordance with Goleman's theory focusing on five factors: (a) self-awareness, (b) self-regulation, (c) motivation, (d) empathy, and (e) social skills. The questionnaire was divided into two parts. The first part includes general information of the respondents including their gender and years of in the industry. The second part consisted of 45 items that allowed participants to share their thoughts and feeling based on their perceived level of EI. Thirty-seven items were positive statements, while the other 8 items were negative.

\subsection{Data Collection and Analysis}

The researcher asked the team assistant of three business units for their cooperation in distributing the questionnaire to their business consultants. The voluntary nature of this study was emphasized. Through a written explanation, the participants were informed of the purpose of the research and that their participation had to be voluntary. After the questionnaires were completed, the raw data was entered into the Statistical Package for the Social Sciences computer program, known as SPSS. Checks for basic descriptive statistics were conducted to ensure the accuracy of data entry. In order to describe the respondents' background information, descriptive statistical techniques, including frequency and percentage were used. To describe the EI levels of the business consultants, mean (M), and standard deviation (SD) were used. The data of each EI factor was 
identified as dependent variables, while the gender and years in the industry were categorized as independent variables. The T-test was employed to determine the differences between EI and other selected independent variables including gender and years in the industry in the study.

\section{Results and Discussion}

To investigate the level of EI among the business consultants working at a consulting firm in Bangkok, Table 1 presented the level of EI among the business consultants of a consulting firm in Bangkok.

Table 1. Level of EI among the business consultants of a consulting firm in Bangkok

\begin{tabular}{lll}
\hline Emotional Intelligence & Mean & SD \\
\hline Motivation & 3.84 & .47 \\
Self-Awareness & 3.81 & .43 \\
Empathy & 3.74 & .47 \\
Social Skill & 3.70 & .41 \\
Self-Regulation & 3.60 & .57 \\
Overall EI level score & 3.74 & .35 \\
\hline
\end{tabular}

As presented in Table 1, the results indicated that the overall EI level of the business consultants was high. This is consistent with Macalam (2009) who stated that the characteristic of business consultants job is to work closely with both internal and external customers in order to help them find the solutions for their business improvement, this position requires the person who has a great deal of communications, and negotiation skills. Working in this role requires a person to have EI competencies in order to perform their job effectively. If they have this skill, their working performance, service quality, customer's perspective toward their service and their revenue are expected to be better. They will eventually have a better work productivity, better relationship with both colleague and clients. As a result, they will sustain their levels of performance and achievement at work.

In order to determine the differences between EI levels of the business consultants with gender and years in the industry, the mean score, standard deviation, and t-test values were used as indicated in the Table 2, and Table 3. The finding shows that there was no significant different between EI level with gender, and years in the industry. In term of gender, Bar - On (2000) claimed that the EI level between men and women does not differ. Bar - On (2000) investigated EI level of 77,000 administrations of the Emotion Quotient Inventory (EQ-i) and found that the overall EI level between men and women are not different. This result also corresponds to the studies conducted by Katyal and Awasthi (2005) who did not find any difference in EI between male and female respondents.

Table 2. Comparison of EI among business consultants of a consulting firm in Bangkok by gender

\begin{tabular}{llllll}
\hline Emotional Intelligence & Gender & $\mathrm{N}$ & $M$ & $S D$ & $\mathrm{t}$ \\
\hline Self-Awareness & male & 39 & 3.80 & .45 & -.12 \\
Self-Regulation & female & 41 & 3.81 & .42 & \\
& male & 39 & 3.62 & .50 & .31 \\
Motivation & female & 41 & 3.58 & .63 & \\
& male & 39 & 3.87 & .46 & .52 \\
Empathy & female & 41 & 3.81 & .48 & \\
\multirow{3}{*}{ Social Skill } & male & 39 & 3.71 & .46 & -.55 \\
& female & 41 & 3.76 & .49 & \\
Overall mean score & male & 39 & 3.75 & .46 & .90 \\
& female & 41 & 3.66 & .35 & \\
& male & 39 & 3.75 & .37 & .21 \\
\hline
\end{tabular}

Note: $*=p<.05$ 
Table 3. Comparison of EI among business consultants of a consulting firm in Bangkok by years in the industry

\begin{tabular}{llcccc}
\hline Emotional Intelligence & Years in the Industry & $\mathrm{N}$ & $M$ & $S D$ & $\mathrm{t}$ \\
\hline Self-Awareness & less than 3 years & 28 & 3.72 & .39 & -1.37 \\
& 3 years and more & 52 & 3.86 & .45 & \\
Self-Regulation & less than 3 years & 28 & 3.67 & .49 & .77 \\
& 3 years and more & 52 & 3.56 & .61 & \\
Motivation & less than 3 years & 28 & 3.80 & .43 & -.52 \\
& 3 years and more & 52 & 3.86 & .49 & \\
Empathy & less than 3 years & 28 & 3.64 & .53 & -1.36 \\
& 3 years and more & 52 & 3.79 & .43 & \\
Social Skill & less than 3 years & 28 & 3.61 & .35 & -1.43 \\
& 3 years and more & 52 & 3.75 & .43 & \\
\hline Total & less than 3 years & 28 & 3.69 & .30 & -1.02 \\
& 3 years and more & 52 & 3.77 & .37 & \\
\hline
\end{tabular}

Note: $*=p<.05$

In terms of years in the industry, the finding of this study was inconsistent with the research of Mishra and Mohapatra (2010). They studied the relationship between EI and work performance among corporate executives in terms of different demographic variables such as gender, academic qualifications and years in the industry. They found that years in the industry was the only factor that was positively related to the EI scores. Similarly, Shipley et al. (2010) studied the effects of EI, age, work experience, and academic performance among undergraduate business students. Sixty-nine percent of students had full-time (40 or more hours per week) work experience and $31 \%$ of students had part-time work experience (39 or less hours per week). The result indicated that the EI level of the student who had a full time job is higher than the student who did not have a full time job. They therefore concluded that work experience has a significantly difference to EI level of the students.

\section{Limitations and Recommendations for Future Research}

This study has some limitations. Firstly, it was conducted only with limited number of respondents who work in a consulting firm in Bangkok. Therefore, the findings did not investigate the EI levels of business consultant in general. Future studies should select respondents from different consulting firms, and increase the number of respondents. Secondly, this study used only a questionnaire to collect data. In order to gain more accuracy, future research could include interviews with business consultants. Using various research methods will generate more information from respondents. Besides, future studies could investigate other demographic variables such as age, and educational background in order to find out if other variables have any significant difference with EI level.

\section{References}

Assanova, M., \& McGuire, M. (2009). Applicability analysis of the emotional intelligence theory. Retrieved from http://www.indiana.edu/ spea/pubs/undergradhonors/honors_vol.3_no.1.pdf

Bar-On, R. (2000). Emotional and social intelligence: Insights from the emotional quotient inventory (EQ-i). In R. Bar-On, \& J. D. A. Parker (Eds.), Handbook of emotional intelligence (pp. 363-388). San Francisco: Jossey-Bass.

Cherniss, C. (2001). Emotional intelligence and organizational effectiveness. In C. Cherniss, \& D. Goleman (Eds.), The emotionally intelligent workplace: How to select for measure, and improve emotional intelligence in individuals, groups, and organizations. San Francisco: Jossey-Bass.

Cooper, R. K. (1997). Applying emotional intelligence in the workplace. Training and development, 51(12), 31-33.

Cooper, R. K., \& Sawaf, A. (1997). Executive EQ: Emotional intelligence in leadership and organizations. New York: The Berkley Publishing Group.

Feldman, J., \& Mulle, K. (2007). Put Emotional Intelligence to Work: EQuip Yourself for Success. Baltimore, Maryland: ASTD Press. 
Goleman, D. (1995). Emotional Intelligence - Why it can matter more than IQ. London: Broomsbury Publishing.

Goleman, D. (1998). Working with emotional intelligence. London: Broomsbury publishing.

Hudak, R. (2000). Identifying management competencies for health care executives: Review of a series of Delphi studies. Journal of Health Administration Education, 213-243.

Intarakamhang., U., \& Sucaromana, A. (2005). Synthesis of research studies in Thailand related to emotional intelligence. Poster Presentation at SASP 34th Annual Conference, Townsville, Australia on 8-10 April 2005.

Johnson, J., \& Erb, D. (2003). EQ in the workplace: A review of how EQ is developed, the implications for focused adult EQ fitness training and the bottom-line impact in the workplace. Retrieved from $\mathrm{http} / / / \mathrm{www}$. seestrategies.com/documents/EQInTheWorkplace9.25.07.pdf

Katyal, S., \& Awasthi, E. (2005). Gender differences in EI among adolescents of Chandigarh, 17(2), 153-155. Retrieved

from http://www.krepublishers.com/02-Journals/JHE/JHE-17-0-000-000-2005-Web/JHE-17-2-085-160-2005-Ab st-PDF/JHE-17-2-153-155-2005-1208-Katyal-S/JHE-17-2-153-155-2005-1208-Katyal-S.pdf

Macalam, R. (2009). Business consulting services: Is it important? Retrieved from $\mathrm{http}: / / \mathrm{www} \cdot$ articleclick.com/Article/Business-Consulting-Services-Is-it-important-/1212884

Mayer, J. D., \& Salovey, P. (1990). Emotional intelligence. Imagination, cognition, and personality, 9, 185-211.

Mayer, J. D., \& Salovey, P. (1997). What is emotional intelligence? Implications for educators. In P. Salovey, \& D. Sluyter, (Eds.), Emotional development, emotional literacy, and emotional intelligence (pp. 3-31). New York, NY: Basic Books.

Mishra, S. P., \& Mohapatra, D. A. K. (2010). Relevance of emotional intelligence for effective job performance: An empirical study. Vikalpa, 35(1).

Mulder, S. (2009). The role of emotional intelligence in the investment management industry - A case study of a South African investment manager. Master's thesis, University of Stellenbosch.

Oginska-Bulik, N. (2005). Emotional intelligence in the workplace: Exploring its effects on occupational stress and health outcomes in human service workers. International Journal of Occupational Medicine and Environmental Health, 18(2), 167-175.

Othman, K. A., Daud, M. N., \& Kassim, R. S. R. (2001). The moderating effect of neuroticism on the relationship between emotional Intelligence and job performance. Australian Journal of Basic and Applied Sciences, 5(6), 801-813.

Schutte, N. S., Malouff, J. M., Hall, L. E., Haggerty, D. J., Cooper, J. T., Golden, C.J., \& Dornhein, L. (1998). Development and validity of a measure of emotional intelligence. Personality and Individual Differences, 25, 167-177. http://dx.doi.org/10.1016/S0191-8869(98)00001-4

Serrat, O. (2009). Understanding and developing emotional intelligence. Retrieved from http://www.adb.org/documents/information/knowledge-solutions/understanding-developing-emotional-intel ligence.pdf

Shipley, L. N., Jackson, J. M., \& Segrest, L. S. (2010). The effects of emotional intelligence, age, work experience, and academic performance. Research in Higher Education, 9, 1-19.

Singh, D. (2001). Emotional intelligence at work: A professional guide. New Delhi: Response Books.

Sjöberg, L. (2001). Emotional intelligence: A psychometric analysis. European Psychologist, 6(2), 79-95. http://dx.doi.org/10.1027//1016-9040.6.2.79

Thongpharp, P. (2003). Emotional quotient of Srinakharinwirot students. Master's thesis, Srinakharinwirot University, Bangkok, Thailand.

Zeidner, M., Matthews, G., \& Roberts, R. (2004).Emotional intelligence in the workplace: A critical review. International Association for Applied Psychology, 53(3), 371-399. http://dx.doi.org/10.1111/j.1464-0597.2004.00176.x 